conducting cover of the jet $\mathrm{G}$ with the thumb and finger, the stream of boiling water may be directed to any place desired. Any excess of pressure simply drives the water slowly through the tube $\mathrm{E}$ into the upper flask, from which the air escapes through $F$.

When a sufficient quantity of water has been used, the clip is opened, the jet $\mathrm{G}$ raised, and the water immediately returns to the lower flask.

OBERIIN, OHIO.

\title{
INTERPRETATION OF SOME RESULTS IN THE ANALYSIS OF EXTRACTS OF FUSTIC.
}

\author{
BY CHARLES S. BOYER.
}

Received April 13, 1895

O OME time since, the writer made several analyses of samples $\checkmark$ of extract of fustic, the method of whose manufacture was at the time unknown. Since there are no recorded analyses of extracts of fustic, so far as I can find, it was thought that a statement of the results and conclusions might be of interest to those engaged in this line of work.

The method of analysis employed is briefly as follows : Five to six grams of the extract were carefully dried in a water-bath until no further loss occurred, the loss being regarded as water. Two to four grams of this dry powder was now put into a Soxhlet extractor and thoroughly and repeatedly exhaused with absolute alcohol, the alcoholic extract distilled, and the residue dried and weighed. The residue was in every case treated with boiling water and tested for morin and maclurin (morin-tannin), the former by adding to one portion a few drops of aluminum sulphate and the latter by adding to another portion some ferric chloride, but in each case with negative results. The residue from the alcoholic extract was ignited in a platinum crucible and the ash subtracted from the matter soluble in absolute alcohol. For the ash percentage, five grams of the powder was carefully ignited in a capacious platinum crucible and the resulting ash weighed.

The results of the analysis of three extracts of fustic found upon the market, together with those of two extracts whose methods of manufacture were known, are put into a table below. 
The results are also calculated upon a dry basis so that they may be compared the better.

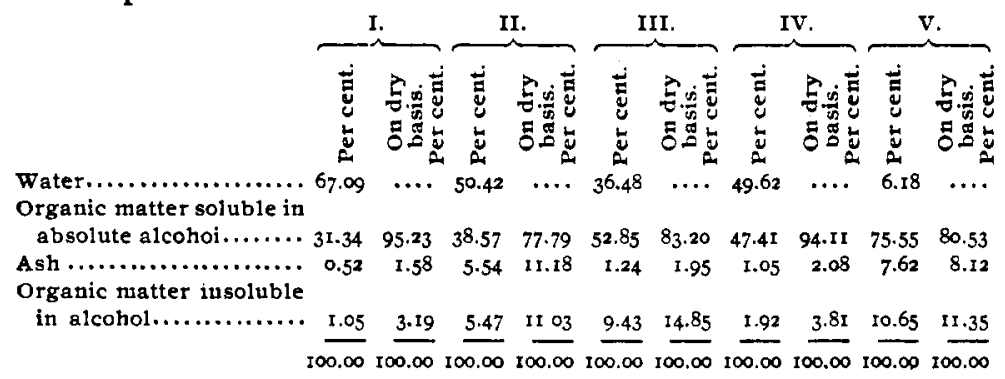

Sample IV was made in an open extractor, the water used in the extraction being brought to a boil before it was run on the wood and the length of time that each "water" remained in contact with the wood being fifteen minutes. Eight "waters" were taken off. Sample $V$ was extracted under five pounds pressure, using seven waters and the weak liquor being evaporated to dryness.

It will be seen that Sample $I$ is very similar to $I V$, while the analysis of II and $V$ are very much alike, especially in that both have a high percentage of ash and approximately the same amounts of organic matter insoluble in alcohol.

It is quite true that different brands of fustic, and even different cargoes of the same brand, contain varying percentages of inorganic matter, or ash. This might lead one to erroneous conclusions were one to depend entirely upon the ash percentages. However, the chief mineral constituents of fustic are lime and magnesia, and as a result of a large number of analyses the writer finds that these two ingredients form another guide in determining the method of extraction. The more pressure used in the extraction, the higher, within certain limits, the ash percentage, and also the larger the amount of lime and magnesia contained in the ash. In the extracts under investigation the percentages of lime and magnesia together were in I, 41.16 per cent.; IV, 46.83 per cent.; II, 68.12 per cent. ; and V, 62.I 5 per cent. of the total ash.

Another ingredient which might prove misleading is extract of quercitron bark. In order to ascertain whether any of these extracts contained this adulterant, a series of dye-tests were 
made depending npon the different affinities of the coloring principles of bark and fustic for alum atul lin norkants, hut in

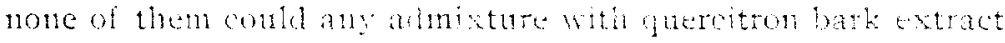
be detected.

The conclusions dram from these analyses and comparisons were that I was made entirely by the "open-extraction" method; II was nade by the "closedextraction" method. using five to eight pounds pressure: and that $\mathrm{MI}$ was extracted in open ressels, but that the changes of "waters" was done minder pressure. The reason for the latter conchusion was that, whice the ash percentage was low, the "extractive matter," or organic matter insoluble in alcohol was very high and the only way that this could happen would be by opening up the fiber of the woud as is the case in open boiling and then applying pressurs, which carried this "extractive matter" into the extracting liquor. These conclusions were subsequently borne out by experiments.

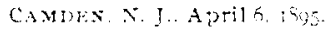

\section{THE TUNGSTATES AND MOLYBDATES OF THE RARE EARTHS.}

H. FANNL R. M. HITCHCOCK.

[Continualfrum pay pos]

b. Five cc. of the cerium sulphate solution were diluted to sixty $c c$, and brought to boiling, when alcohol was added, five cc. at a time, until sixty-five cc. had gone in, but the solution still remained clear. To this hot solution the cerium sulphate solution was added in the same way as the alcohol had been. The first addition of five cc. caused a precipitate to form, which redissolved at once. The second addition of five cc. caused a precipitate which dissolved again very slowly, and with the third addition the cerium sulphate came down in fine needles.

It was evident that the amount of alcohol which had been used in experiments 8,9 and 10 , with the sodium molybdate, had not been sufficiently great to cause by itself the precipitation of the cerium sulphate. The experiments were, therefore, repeated, the conditions being slightly varied.

Experiment $I J$. Ten $c c$. sodium molybdate solution were diluted to I00 cc., and fifteen $\mathrm{cc}$. of the cerium sulphate solution added. To this, in the cold, fifty $\mathrm{cc}$. of ninety-five per cent. alcohol were added very gradually, and with constant stirring. The 